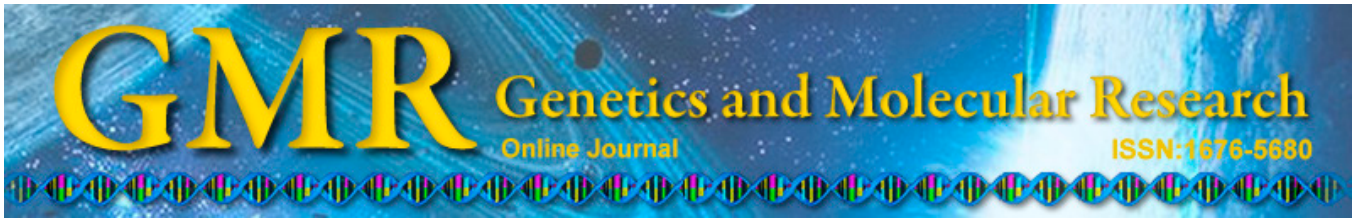

\title{
Effect of continuous infusion of midazolam on immune function in pediatric patients after surgery
}

\author{
H.B. Lu ${ }^{1}$, Y.P. Jia ${ }^{1}$, Z.H. Liang ${ }^{1}$, R. Zhou ${ }^{1}$ and J.Q. Zheng ${ }^{2}$ \\ ${ }^{1}$ Department of Anesthesiology, Children's Hospital of Zhengzhou, Zhengzhou, \\ Henan, China \\ ${ }^{2}$ Department of Anesthesiology, West China Hospital, Sichuan University, \\ Chengdu, Sichuan, China \\ Corresponding author: H.B. Lu \\ E-mail: luhaibing255@sohu.com
}

Genet. Mol. Res. 14 (3): 10007-10014 (2015)

Received December 20, 2014

Accepted May 18, 2015

Published August 21, 2015

DOI http://dx.doi.org/10.4238/2015.August.21.7

\begin{abstract}
The current study was performed to investigate the effects of midazolam on immune function in pediatric patients after surgery and possible mechanism involved. Patients who needed sedation for more than 2 consecutive days after undergoing surgery in the Pediatric Surgery Department of our hospital were enrolled for the study. Fiftysix patients (5-14 years old) were randomly divided into midazolam and propofol treatment groups $(\mathrm{N}=28$ each in each group). Pediatric patients received midazolam or profolol via continuous intravenous administration, and their plasma cytokine levels were compared after $48 \mathrm{~h}$. Cultured rat C6 brain glioma cells were pretreated with a range of concentrations of midazolam or propofol for 60 minutes prior to incubation with $10 \mathrm{ng} / \mathrm{mL}$ IL- $1 \beta$ in serum-free medium or vehicle for $36 \mathrm{~h}$. IL-6 concentration was subsequently measured using ELISA. In comparison with levels measured before the infusion of midazolam for $48 \mathrm{~h}$, concentrations of all cytokines decreased, with the differences in IL-1 $\beta$, IL-8, and TNF- $\alpha$ concentrations reaching significance (all $\mathrm{P}<$
\end{abstract}


0.05). Midazolam significantly suppressed the IL-1 $\beta$-induced release of IL-6 in rat C6 glioma cells. This inhibition was concentration-dependent between 0.3 and $3 \mu \mathrm{M}$, with $3 \mu \mathrm{M}$ concentration of midazolam decreasing the IL-1 $\beta$-induced release of IL- 6 by $43.58 \%$. Midazolam can significantly inhibit the release of cytokines in pediatric patients after surgery. One of the mechanisms may be the inhibition of IL-1 $\beta$ induced release of IL-6 in the central nervous system.

Key words: Midazolam; C6 glioma cells; Cytokines

\section{INTRODUCTION}

Midazolam is a drug belonging to the benzodiazepine family. It is used for premedication before the induction of anesthesia, in the induction and maintenance of general anesthesia, and to achieve conscious-sedation during diagnostic or therapeutic procedures (Olkkola and Ahonen, 2008). Previous studies have shown that midazolam can affect the immune function in elderly, critically ill patients (Helmy and Al-Attiyah, 2001). There are two types of benzodiazepine receptors: the central type benzodiazepine receptors (CBRs), which are coupled to the $\mathrm{GABA}_{\mathrm{A}}$ inotropic receptors, and peripheral type benzodiazepine receptors (PBRs), which are not coupled to GABA (Casellas et al., 2002; Weissman and Raveh, 2003). Although midazolam was shown to bind and activate both CBRs and PBRs (Matsumoto et al., 1994), the sedative and hypnotic effects of midazolam are mediated through its action on neuronal CBRs (Helmy and Al-Attiyah, 2001; Casellas et al., 2002; Olkkola and Ahonen, 2008), which are expressed only in the central nervous system (Casellas et al., 2002). The expression of CBRs coupled to $\mathrm{GABA}_{\mathrm{A}}$ receptors on astrocytes was shown to be altered in cell maturation, differentiation, and activation (Tateishi et al., 2006). While the expression of PBRs in the normal human brain is very low, the expression in astrocytes and microglial cells is increased upon glial activation in inflammation, brain injury, neurodegeneration, and neuroglioma (Casellas et al., 2002; Weissman and Raveh, 2003). C6 cells are derived from rat glioma cells, which express both PBRs and CBRs (Starosta-Rubinstein et al., 1987). These cells are therefore suitable for studying the function of PBRs in astrocytes.

Animal studies have shown that midazolam can improve neuronal recovery after hypoxia and ischemia (Lei et al., 2009). Cytokines, particularly interleukin (IL)-1 $\beta$ and tumor necrosis factor (TNF), can activate the immune system and further aggravate brain injury (Green, 2008). Midazolam can inhibit the expression of IL-6 mRNA in human peripheral blood mononuclear cells (Miyawaki et al., 2001), and suppress the lipopolysaccharide (LPS)induced release of nitric oxide and TNF- $\alpha$ in rat microglial cells via PBRs (Wilms et al., 2003). Therefore, we hypothesized that midazolam may play a role in the regulation of immune function in the central nervous system. However, the exact mechanism of the effect of midazolam on the immune function in the central nervous system remains unclear.

Under physiological conditions, IL-1 $\beta$ and pro-inflammatory cytokines are expressed at low levels in the central nervous system (Gibson et al., 2004; Allan et al., 2005; Simi et al., 2007). IL-1 plays a role in the physiological processes involved in sleep and synaptic plasticity (Allan et al., 2005). In traumatic brain injury, stroke, and neurodegenerative diseases, IL-1 $\beta$ levels in cerebrospinal fluids are increased (Allan et al., 2005). IL-1 $\beta$ can induce the microglia and astrocytes to produce other cytokines, such as TNF- $\alpha$ and IL-6 (Allan et al., 2005; Simi 
et al., 2007). A previous study in C6 glioma cells found that IL-1 $\beta$ significantly increases IL-6 synthesis (Tanabe et al., 2010). Our current study therefore aimed to investigate the effect of midazolam on the immune function in pediatric patients and its possible mechanism.

\section{METHODS}

\section{Study subjects and grouping}

Patients in the Pediatric Surgery Department of our hospital who needed sedation treatment for more than 2 consecutive days after surgery were selected for potential participation. A total of 56 patients, aged 5-14 years, were recruited for the study. Pediatric patients were randomly divided into midazolam and propofol treatment groups using a random number table, with each group having 28 patients. All patients had no medical history of epilepsy, drug abuse, Glasgow coma scale $<15$ points, diseases of immune and endocrine systems, cancer, chronic inflammation, or severe kidney or liver disease. Additionally, we excluded patients who were receiving steroids or drugs affecting the immune system. The study had been approved by Human Subjects Research Committee of Children's Hospital of Zhengzhou.

\section{Medication administration}

In the midazolam group, patients were first intravenously administered $0.05-0.08 \mathrm{mg} / \mathrm{kg}$ midazolam (Jiangsu Nhwa Pharmaceutical Group Co., Ltd., batch No. H19990027, Xuzhou, Jiangsu, China), followed by $0.02-0.06 \mathrm{mg} / \mathrm{kg}$ midazolam administered by continuous intravenous infusion. In the propofol group, patients were first intravenously administered $1.5-2.0 \mathrm{mg} / \mathrm{kg}$ propofol (XiAn LiBang Pharmaceutical Co., Ltd., batch No. H20010368, XiAn, Shanxi, China), followed by $0.5-1.5 \mathrm{mg} / \mathrm{kg}$ midazolam administered by continuous intravenous infused. The actual amount of propofol or midazolam administered per hour was recorded for each patient. Remaining treatments were implemented in accordance with the physician's directions.

\section{Individual observation of cytokine levels}

A sample $(10 \mathrm{~mL})$ of central venous blood was collected immediately before dosing and $48 \mathrm{~h}$ following the dosing. Following centrifugation at $4^{\circ} \mathrm{C}$, the separated plasma was stored at $-80^{\circ} \mathrm{C}$ until analysis. Plasma levels of IL-1 $\beta$, IL-2, IL-6, IL- 8 , TNF- $\alpha$, and interferon- $\gamma(\mathrm{IFN}-\gamma)$ were measured by ELISA.

\section{Cell culture}

C6 rat glioma cells were purchased from Cyagen Biosciences (item No. RBGC630001, Guangzhou, Guangdong, China). Cells were seeded onto $35-\mathrm{mm}\left(5 \times 10^{4}\right.$ cells/plate $)$ or $90-\mathrm{mm}\left(2 \times 10^{5}\right.$ cells/plate $)$ culture plates and stored at $37^{\circ} \mathrm{C}$ in Dulbecco's modified Eagle medium (DMEM) containing 10\% fetal bovine serum under humid conditions with $5 \% \mathrm{CO}_{2} / 95 \%$ air. Six days later, the medium was replaced with serum-free DMEM and the cells were used for experiments after 24 hours. Cells were pretreated with a range of concentrations of midazolam or propofol for 60 minutes, prior to incubation with $10 \mathrm{ng} / \mathrm{mL} \mathrm{IL-1} \beta$ or vehicle for 36 hours. 


\section{IL-6 levels}

IL-1 $\beta(10 \mathrm{ng} / \mathrm{mL})$ or vehicle was added to the serum-free medium and the cells were cultured for 36 hours. The medium was collected and the concentration of IL-6 was measured by ELISA.

\section{Statistical analysis}

The SPSS 19.0 software (IBM Co, Armonk, NY, USA) was used for all statistical analyses. The $t$-test or analysis of variance was used for comparisons between the two treatment groups. $\mathrm{P}<0.05$ was considered to be statistically significant.

\section{RESULTS}

\section{Comparison of immune indices in patients measured before and after dosing}

Before dosing, no statistically significant differences were observed in levels of studied cytokines between the patients in two treatment groups (comparison between groups, all $\mathrm{P}$ $>0.05$ ). As presented in Table 1, levels of all studied cytokines were reduced after continuous administration of midazolam for 48 hours, with significant decreases observed in IL- $1 \beta$, IL-8, and TNF- $\alpha$ levels, compared with the measurements obtained before dosing $(\mathrm{P}<0.05)$.

In the propofol group, IL- $1 \beta$, IL- 8 , and TNF- $\alpha$ levels were significantly increased after continuous administration of propofol for 48 hours, compared to the measurements obtained before dosing $(\mathrm{P}<0.05)$.

\begin{tabular}{|c|c|c|c|c|}
\hline & & Concentration before dosing $(\mu \mathrm{g} / \mathrm{L})$ & Concentration after dosing $(\mu \mathrm{g} / \mathrm{L})$ & $\mathrm{P}$ \\
\hline \multirow[t]{6}{*}{ Midazolam group $(\mathrm{N}=28)$} & IL- $1 \beta$ & $5.69 \pm 2.98$ & $4.52 \pm 1.21$ & 0.011 \\
\hline & IL-2 & $1023.33 \pm 214.78$ & $935.07 \pm 182.34$ & 0.069 \\
\hline & IL-6 & $119.02 \pm 83.04$ & $94.02 \pm 68.34$ & 0.043 \\
\hline & IL-8 & $4.53 \pm 0.92$ & $3.99 \pm 0.87$ & 0.051 \\
\hline & TNF- $\alpha$ & $9.39 \pm 3.80$ & $6.87 \pm 4.01$ & 0.035 \\
\hline & INF- $\gamma$ & $110.34 \pm 18.92$ & $112.80 \pm 14.35$ & 0.073 \\
\hline \multirow{6}{*}{ Propofol group $(\mathrm{N}=28)$} & IL-1 $1 \beta$ & $5.35 \pm 2.02$ & $6.78 \pm 1.09$ & 0.020 \\
\hline & IL-2 & $1018.45 \pm 212.40$ & $1021.34 \pm 193.20$ & 0.072 \\
\hline & IL-6 & $115.21 \pm 82.00$ & $121.02 \pm 72.30$ & 0.032 \\
\hline & IL-8 & $4.62 \pm 0.89$ & $4.02 \pm 0.65$ & 0.055 \\
\hline & TNF- $\alpha$ & $9.22 \pm 3.74$ & $12.80 \pm 4.21$ & 0.020 \\
\hline & INF- $\gamma$ & $115.64 \pm 18.20$ & $114.56 \pm 15.77$ & 0.065 \\
\hline
\end{tabular}

All results are reported as means \pm standard deviation. Blood cytokine levels measured before and after dosing were compared using the $t$-test. $\mathrm{P}<0.05$ indicated a statistically significant difference.

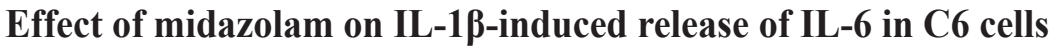

Previous reports indicated that IL- $1 \beta$ can significantly induce the expression of IL-6 mRNA in C6 glioma cells and stimulate the release of IL-6 (Wilms et al., 2003). Figure 1 presents IL-6 concentrations measured in C6 glioma cells after pretreatment with a range of concentrations of midazolam for 60 minutes, followed by a 36-hour incubation with $10 \mathrm{ng} /$ 
$\mathrm{mL}$ of IL-1 $\beta$ (the upper curve) or vehicle (the lower curve). The results show that midazolam significantly inhibits IL- $1 \beta$-induced release of IL-6, with the inhibition being concentrationdependent between 0.3 and $3 \mu \mathrm{M}$ (Figure 1).

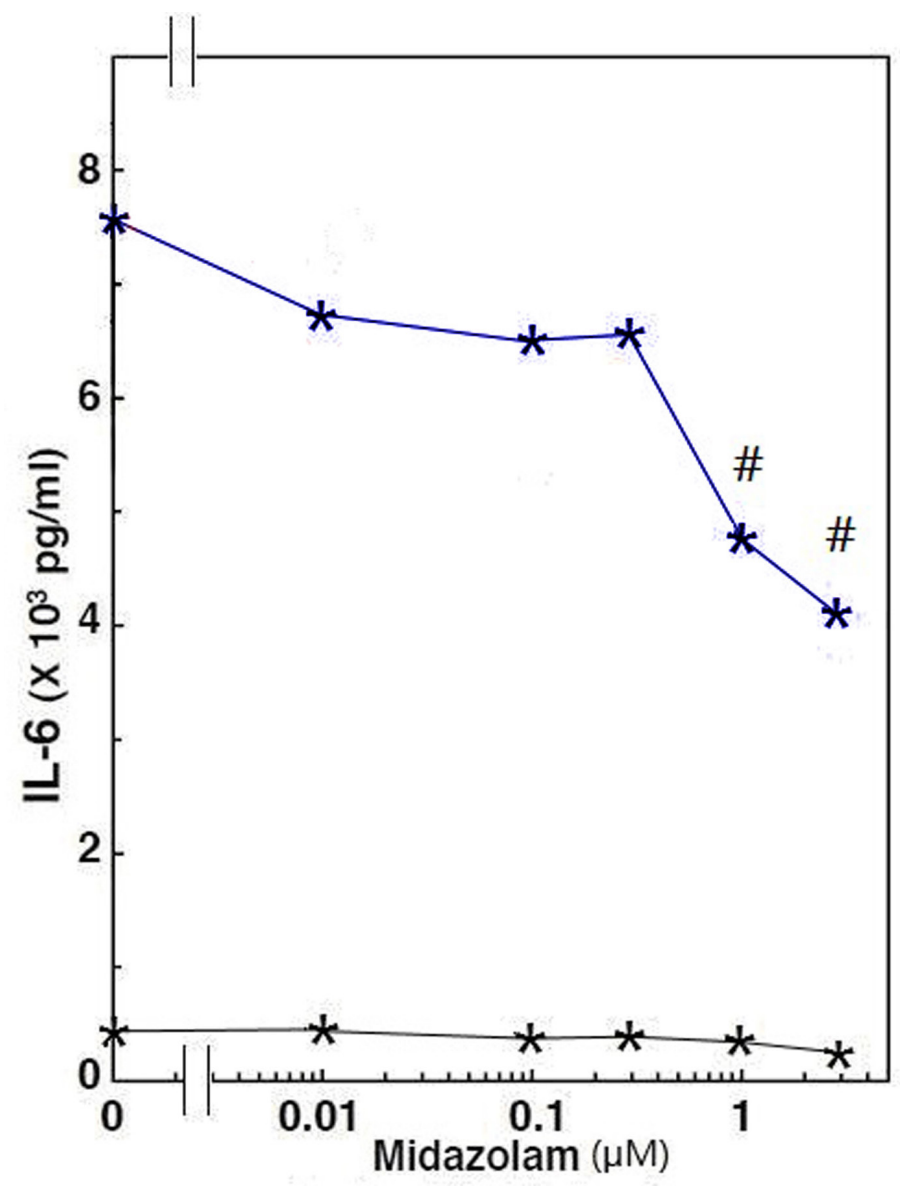

Figure 1. Concentrationsof IL-6 were measured following 60-minute pretreatment of C6 glioma cells with a range of concentrations of midazolam and 36-hour incubation with IL-1 $\beta$ (10 ng/mL; upper curve) or vehicle (lower curve). "Significantly different, compared to the single use of IL- $1 \beta, \mathrm{P}<0.05$. Pairwise comparisons were performed using analysis of variance.

At the highest $(3 \mu \mathrm{M})$ concentration of midazolam, IL-1 $\beta$-induced release of IL-6 was decreased by $43.58 \%$.

\section{Effect of propofol on IL-1 $\beta$-induced release of IL-6 in C6 cells}

Figure 2 presents the IL-6 levels measured in C6 glioma cells pretreated with a range of concentrations of propofol for 60 minutes prior to incubation with $10 \mathrm{ng} / \mathrm{mL}$ of IL- $1 \beta$ (the upper curve) or vehicle (the lower curve) for 36 hours. The results show that propofol did not significantly inhibit IL-1 $\beta$-induced release of IL-6 in the $0-10 \mu \mathrm{M}$ concentration range (Figure 2). 


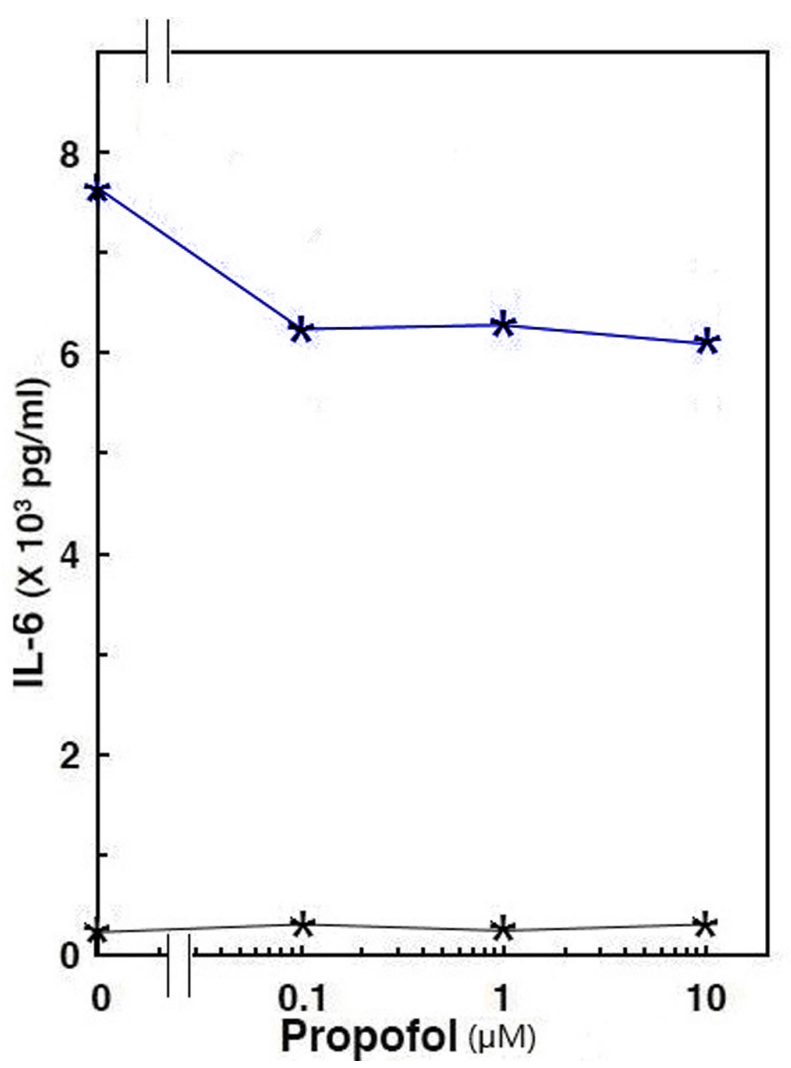

Figure 2. Concentrations of IL-6 were measured following 60-minute pretreatment of $\mathrm{C} 6$ glioma cells with a range of concentrations of propofol and 36-hour incubation with $10 \mathrm{ng} / \mathrm{mL}$ of IL-1 $\beta$ (upper curve) or vehicle (lower curve). Pairwise comparisons were performed using analysis of variance.

\section{DISCUSSION}

In this study, midazolam administration was found to decrease plasma levels of cytokines in children, significantly decreasing IL- $1 \beta$, IL- 6 , and TNF- $\alpha$ concentrations, while propofol administration significantly was observed to increase the concentrations of IL-1 $\beta$, IL- 6 , and TNF- $\alpha$. Further study found that midazolam significantly inhibits IL-1 $\beta$-induced release of IL-6 in rat C6 glioma cells, while propofol elicits no significant effect on IL-1 $\beta$-induced release of IL-6.

Benzodiazepines are known to play a role in the regulation of the immune system (Miyawaki et al., 2001; Casellas et al., 2002; Wilms et al., 2003). Midazolam, a drug belonging to the benzodiazepine family, is commonly used in clinics and can inhibit the immune function. Previous studies have found that the prolonged intravenous administration of midazolam (more than 48 hours of continuous medication) can significantly affect the immune function in elderly patients after surgery and inhibit the production of IL-1 $\beta$, IL- 6 , and TNF- $\alpha$. Conversely, propofol, another commonly used sedative drug, promotes the productions of IL-1 $\beta$, IL-6, and TNF- $\alpha$. It is widely perceived that the immunological parameters should be monitored in patients who are aged, physically weak, or immunocompromised while undergoing treatment with midazolam (Helmy and Al-Attiyah, 2001). A study performed in pediatric 
patients following continuous intravenous administration of midazolam after surgery found a trend towards a decrease in immunological indices 48 hours after treatment, compared with the measurements before treatment, with significant decreases observed in levels of IL-1 $\beta$, IL6 , and TNF- $\alpha$. The finding of this study, that IL- $1 \beta$, IL- 6 , and TNF- $\alpha$ levels are significantly increased in propofol-treated patients, is consistent with the results of previous studies (Tanabe et al., 2010). To further clarify the effect of midazolam on the above-mentioned cytokines and the mechanism of its action, we investigated the effects of midazolam and propofol on IL-1 $\beta$ induced release of IL-6 in rat C6 glioma cells.

Previous studies have found that midazolam inhibits the expression of IL-6 mRNA in human peripheral blood mononuclear cells (Miyawaki et al., 2001), and inhibits the LPSinduced release of nitric oxide and TNF- $\alpha$ in rat microglial cells via PBRs (Wilms et al., 2003). In patients with traumatic brain injury, stroke, and neurodegenerative diseases, IL-1 $\beta$ levels are elevated in the cerebrospinal fluid (Allan et al., 2005). High levels of brain IL-1 $\beta$ after acute injury are found in the microglial cells, with astrocytes also producing IL-1 $\beta$ (Gibson et al., 2004; Allan et al., 2005; Simi et al., 2007). IL-1 $\beta$ can induce the microglia and astrocytes to produce other cytokines, such as TNF- $\alpha$ and IL-6 (Allan et al., 2005; Simi et al., 2007). Previously study performed has found that IL- $1 \beta$ can significantly induce the synthesis of IL-6 in C6 glioma cells (Tanabe et al., 2010). The results of the same study also suggest that IL-1 $\beta$ significantly induces the expression of IL-6 mRNA and stimulates the release of IL-6 in C6 glioma cells (Tanabe et al., 2010). Our current study shows that midazolam can significantly inhibit IL-1 $\beta$-induced release of IL-6 in rat C6 glioma cells. The inhibitory effect was concentration-dependent between 0.3 and $3 \mu \mathrm{M}$ concentrations, with $3 \mu \mathrm{M}$ midazolam concentration decreasing the IL- $1 \beta$-induced release of IL- 6 by $43.58 \%$. Conversely, propofol elicited no significant effect on IL-1 $\beta$-induced release of IL- 6 . These results, combined with the mentioned clinical findings, demonstrate that midazolam inhibits the release of cytokines, and suggest that the inhibition of the IL-1 $\beta$-induced release of IL- 6 in the central nervous system may be one of the possible mechanisms of action.

\section{CONCLUSIONS}

In summary, this study demonstrates that prolonged intravenous administration of midazolam (more than 48 hours) in pediatric patients after surgery has an inhibiting effect on the release of cytokines, with the inhibition of the IL-1 $\beta$-induced release of IL-6 in the central nervous system being one possible mechanism of action. These findings have a vital significance, with implications that could guide future clinical applications of midazolam.

\section{REFERENCES}

Allan SM, Tyrrell PJ and Rothwell NJ (2005). Interleukin-1 and neuronal injury. Nat. Rev. Immunol. 5: 629-640.

Casellas P, Galiegue S and Basile AS (2002). Peripheral benzodiazepine receptors and mitochondrial function. Neurochem. Int. 40: 475-486.

Gibson RM, Rothwell NJ and Le Feuvre RA (2004). CNS injury: the role of the cytokine IL-1. Vet. J. 168: 230-237.

Green AR (2008). Pharmacological approaches to acute ischaemic stroke: reperfusion certainly, neuroprotection possibly. Br. J. Pharmacol. 153: S325-S338.

Helmy SA and Al-Attiyah RJ (2001). The immunomodulatory effects of prolonged intravenous infusion of propofol versus midazolam in critically ill surgical patients. Anaesthesia 56: 4-8.

Lei B, Popp S, Cottrell JE and Kass IS (2009). Effects of midazolam on brain injury after transient focal cerebral ischemia in rats. J. Neurosurg. Anesthesiol. 21: 131-139. 
Matsumoto T, Ogata M, Koga K and Shigematsu A (1994). Effect of peripheral benzodiazepine receptor ligands on lipopolysaccharide-induced tumor necrosis factor activity in thioglycolate-treated mice. Antimicrob. Agents Chemother. 38: 812-816.

Miyawaki T, Sogawa N, Maeda S, Kohjitani A, et al. (2001). Effect of midazolam on interleukin-6 mRNA expression in human peripheral blood mononuclear cells in the absence of lipopolysaccharide. Cytokine 15: 320-327.

Olkkola KT and Ahonen J (2008). Midazolam and other benzodiazepines. Handb. Exp. Pharmacol. 182: 335-360.

Simi A, Tsakiri N, Wang P and Rothwell NJ (2007). Interleukin-1 and inflammatory neurodegeneration. Biochem. Soc. Trans. 35: 1122-1126.

Starosta-Rubinstein S, Ciliax BJ, Penney JB, McKeever P, et al. (1987). Imaging of a glioma using peripheral benzodiazepine receptor ligands. Proc. Natl. Acad. Sci. U. S. A. 84: 891-895.

Tanabe K, Matsushima-Nishiwaki R, Dohi S and Kozawa O (2010). Phosphorylation status of heat shock protein 27 regulates the interleukin-1 $\beta$-induced interkeukin-6 synthesis in C6 glioma cells. Neuroscience 170: 1028-1034.

Tateishi N, Shimoda T, Manako J, Katsumata S, et al. (2006). Relevance of astrocytic activation to reductions of astrocytic GABAA receptors. Brain Res. 1089: 79-91.

Weissman BA and Raveh L (2003). Peripheral benzodiazepine receptors: on mice and human brain imaging. J. Neurochem. 84: $432-437$.

Wilms H, Claasen J, Röhl C, Sievers J, et al. (2003). Involvement of benzodiazepine receptors in neuroinflammatory and neurodegenerative diseases: evidence from activated microglial cells in vitro. Neurobiol. Dis. 14: 417-424. 